\title{
ACTITUDES SOCIALES Y POLÍTICAS EN LA DENOMINADA RECUPERACIÓN DE LA MEMORIA HISTÓRICA. GALICIA. EL PROYECTO DE INVESTIGACIÓN INTERUNIVERSITARIO «NOMES E VOCES»
}

Lourenzo Fernández Prieto

Un año después de la participación en el curso de verano organizado por el profesor Glicerio Sánchez Recio he intentado actualizar en lo posible un texto que dio lugar a un amplio y a mi juicio interesante debate. Se presenta primero una aproximación a las actitudes sociales y políticas para avanzar después sintéticamente algunos resultados del proyecto de investigación «Nomes y Voces» desarrollado en Galicia desde el año 2005 y explicar sumariamente sus planteamientos y objetivos.

\section{Algunos presupuestos de partida: sobre memorias, olvidos y transiciones}

No hubo un pacto de silencio de los políticos en la Transición sino un pacto del que participó la inmensa mayoría de la sociedad. Un acuerdo general de mirar hacia adelante y olvidar lo que el franquismo había hecho recordar hasta el último minuto de la vida del Dictador: la guerra como victoria de unos y derrota de otros. Esa, llamémosla, vocación social, estuvo por supuesto aderezada y representada en aquella ruptura pactada de la que la Ley de Amnistía es un ejemplo perfecto: el franquismo reformista amnistiaba a los antifranquistas de sus «delitos» contra el régimen, a la vez que los franquistas quedaban también amnistiados de unos delitos no reconocidos. Los demócratas celebraron lo primero pero lo segundo simplemente ocurrió y sólo fue reivindicado como amnistía por los herederos del franquismo cuando décadas más tarde se reclaman difusamente 
responsabilidades en el contexto de lo que se ha dado en llamar recuperación de la memoria histórica, a partir de $1996^{1}$.

El entendimiento entre Adolfo Suárez, como dirigente de la generación heredera del Régimen que ganó la guerra, y Santiago Carrillo, como representante de la generación que había hecho y perdido la guerra, y por ende de la opción política más conspicuamente identificada con el bando perdedor y con el antifranquismo, representa a la perfección este acuerdo fundacional y las razones políticas del mismo. Pero el triunfo social de aquel acuerdo hay que buscarlo en la voluntad social de mirar al futuro (democracia y Europa) y olvidar el pasado recién fenecido (Franco) que predomina desde 1976. Ello no significa que el pasado que se quiere olvidar esté ausente. Al contrario, el recuerdo de la guerra y el temor a su repetición estaba tan presente y era tan tangible en la sociedad española de la época que de hecho se materializa varias veces entre 1976 y 1981 en actos de violencia y proclamas golpistas y, de forma rotunda, en el intento de golpe de Estado del 23-F de 1981². Justamente eso, la amenaza de «volver a las andadas» es lo que el franquismo residual quiere hacer patente por diferentes vías hasta la materialización del golpe, y justamente eso es lo que la sociedad quiere superar y olvidar. El golpe frustrado será la ocasión para superar definitivamente aquella amenaza que, como recordatorio permanente, había constituido un elemento central de legitimación de la Dictadura a lo largo de cuatro décadas. El pacto social de la Transición requería y quería el olvido del pasado.

En la actualidad aquel pacto mudó. Aquel acuerdo que aquí definimos como social pertenecía a un momento (la Transición) que ha pasado cronológicamente y a una generación (la que la protagoniza) que en buena medida ha ido siendo relevada. No podría decirse si aquel pacto sigue o no vigente pero en todo caso está totalmente en cuestión y así se hace ver, en forma de crítica, en el debate político actual a propósito de numerosos asuntos. Diríamos que son cada vez menos los sectores sociales, políticos o intelectuales que reconocen las razones

1. Compartimos el momento seminal de arranque de este proceso indicado entre otros por Pedro Ruiz TorRes (2007), «Los discursos de la memoria histórica en España», Historia Nova, 7 , en un artículo que tercia en la discusión que mantienen en la misma publicación Santos Juliá y Francisco Espinosa. Una fecha, la de 1996, que no en vano coincide también con la publicación del conocido e influyente libro de Paloma Aguilar.

2. Sobre el particular Sartorius y SABio (2007), El final de la Dictadura, Madrid, Temas de Hoy, detallan profusamente la violencia y las incertidumbres políticas y sociales del período de la Transición, desde la perspectiva y la explicación que deriva de la posición del PCE en aquellos momentos patente en el libro. J. Cercas (2009), Anatomía de un instante, lo ha novelizado con acierto aunque expresando repetidamente la perplejidad e ignorancia de por qué la sociedad española se paraliza aquella noche de secuestro del Parlamento. 
y la necesidad de aquel pacto de olvido treinta años más tarde. Pero tampoco ha sido sustituido por otro. De hecho, en la última década se ha ido imponiendo la necesidad de conocer (y reconocer) más sobre las víctimas de la represión y la guerra pero sigue siendo un tabú absoluto, no sólo judicial sino también social e intelectual, indagar sobre los victimarios, cuestión esta que no ha sido objeto todavía de pocas investigaciones formales. Es más, es casi una obviedad que la investigación sobre las víctimas, para poder llevarse a cabo, ha de prescindir necesariamente de la indagación sobre los verdugos. Es un acuerdo no escrito pero suficientemente consensuado como para que no se haya roto. Y con el que algunos historiadores nos hemos manifestado tácitamente de pleno acuerdo en el diseño de nuestros trabajos. Las escasas fisuras sobre este asunto, no siempre premeditadas, han terminado por tener casi siempre una respuesta judicial (Francisco Espinosa, 2009).

«Ir de la ley a la ley», como expresó Torcuato Fernández Miranda resultó ser la vía del franquismo para buscar una salida a sí mismo. El programa de la Transición ejecutado por Suárez fue absolutamente fiel a esta idea. Y parece necesario advertir que este programa de salida del franquismo tiene mucho que ver con sus orígenes y también con los problemas de memoria que aquejan a la sociedad española en el presente. Como consecuencia, los procesos kafkianos que empleando el marco legal liberal español de la República y la Restauración se usaron para destruir a los demócratas en el momento del golpe de Estado de 1936 siguen hoy siendo legales en España ${ }^{3}$. Sólo Frank Kafka pudo imaginar y anteceder en su obra el uso de los instrumentos de poder del Estado para destruir a las personas. Esa sensación, la de estar leyendo El Proceso (1914 [1925]), es la que asalta cuando se lee alguno de los miles de procesos del período depositados en los archivos militares. Miles de Josef K., enjuiciados acusados de graves crímenes por los que se pide la máxima pena sin que sepan de qué se les acusa. Sobre aquellos procesos urgentes se sobrepusieron las políticas de la Victoria (Cazorla, 2000) que asentaron la aplicación retrospectiva de las nuevas leyes. La consecuencia es que hoy en día sigue siendo legal que entre 1936 y 1945, y de forma extendida hasta 1975, se procesaran, fusilaran, encarcelaran y depuraran a miles de personas. No se podrá acusar de exageración a quien afirma que aquellos procesos fueron justos en cuanto legales o ajustados a la ley, todavía, en la España de hoy, por mucho que se hayan establecido reparaciones morales o incluso económicas de diverso tipo.

3. Como es bien sabido, y sin necesidad de extenderme en el asunto, conviene tener presente que en la denominada Ley de la Memoria Histórica (2006) no se logró materializar la anulación efectiva de aquellos juicios. 
No es extraño por ello que tengamos actualmente problemas con la Memoria en estos países que forman España, en donde hubo una Dictadura que colaboró con los nazis y los fascistas hasta 1945 e incluso los acogió después de esa fecha hasta que murieron. Pero tampoco puede haber otro punto de partida para resolverlo que el que plantea, de forma tan simple como contundente, el profesor Reyes Mate, último Premio de Ensayo (2009): «Las sociedades que sufrieron un pasado dictatorial y una guerra civil no pueden construir su futuro pasando página». En esa misma línea entendemos que para los historiadores de oficio la única alternativa es el conocimiento del pasado sin cortapisas de ningún tipo, lo que siendo una necesidad cívica es, en primer lugar, un requerimiento intelectual e historiográfico. Esta necesidad así planteada es, por lo tanto, contradictoria con focalizar la atención exclusivamente en las víctimas, tal como hacemos y defendemos en este momento, pero acabará por ser de forma extensa una propuesta ineludible en un futuro no muy lejano. No es la fe ni el trabajo lo que nos hará libres pero sí el conocimiento.

Como consecuencia de la forma en que se pudo realizar la Transición y para entender el problema que tenemos con la memoria, es preciso señalar que los herederos políticos de la República abdicaron de su recuerdo y, desde luego de su reivindicación, después de 1978. Se asumió la construcción del olvido como una necesidad con largas raíces, pero que contó -y es necesario recalcarlo para evitar las visiones conspirativas- con un gran consenso social y, por supuesto, también político. De hecho el programa de la Transición ya está siendo formulado, en una versión precoz y con un objetivo evidentemente diferente, por el PCE desde la segunda mitad de los años 50 al propugnar la denominada «política de reconciliación nacional» que fue calando en muchos sectores y elites del antifranquismo -vinculados o no al PC-a lo largo de 20 años. Después de 1975 aquel propicio caldo de cultivo será aprovechado por los propios franquistas reformistas como uno de los elementos centrales del programa de la Transición o, por decirlo de otro modo, servirá de enlace funcional y ya consolidado con sus propuestas. La idea de reconciliación está presente en todos los discursos reformistas que proceden del franquismo y, a diferencia del PC y sus organizaciones, ellos cuentan con los resortes y la fuerza para hacerlo factible. En todo caso esto permitiría entender la convergencia sobre las ideas de reconciliación entre diferentes sectores, ya muy labradas dende 1956, y que desde 1975 parecen responder además a una amplia aspiración social.

No deja de ser bien significativo que la única excepción permanente y notable a este planteamiento colectivo español haya procedido de -o pueda personalizarse en- Jorge Semprún, que reúne en su persona, con la memoria de la guerra española, la de la guerra europea contra el fascismo y la de los campos de 
concentración, también la del estalinismo y del antiestalinismo precoz, alguien que convivió - precisamente- con Halbwachs en Buchenbald y que es de los primeros, sino el primero entre los españoles, en utilizar el término memoria histórica en sus obras. Y que fue precisamente -lo que no es en absoluto contradictorio sino esclarecedor- uno de los dirigentes comunistas que promovió aquella nueva política de reconciliación nacional en el interior, fraguó nuevas alianzas y acercó al antifranquismo del PC a una nueva generación de elites universitarias, antes de ser expulsado en $1964^{4}$.

Aquella apelación permanente de Semprún, su reivindicación de reconciliación y perdón sin olvido (sin duda no fue el único pero sí el primero y el que más públicamente, coherentemente y reiteradamente lo formuló en estas últimas décadas), es la que al fin ha calado socialmente, en una parte de la sociedad y la política española. La misma parte que sintiéndose heredera de la República y la derrota olvidó una y otra durante más de un cuarto de siglo. Pero no en la otra parte, como no podía ser de otro modo, cuando hablamos de las consecuencias de una guerra civil. De todos modos el consenso de la Transición tuvo efectos evidentes en términos de memoria: el olvido y la idea de reconciliación. El olvido, con su componente de ausencia de conocimiento, y la idea de una sociedad reconciliada con su pasado, como demostraría la capacidad para realizar una Transición ejemplar, y evidenciarían dos decenios de régimen democrático y tres alternancias en el poder. Ambas circunstancias explicarían que la actual derecha española, una vez que llega al poder en 1996, intente expresar sus ansias de modernidad y normalidad en su deseo de superación del pasado traumático y en su intención de no sentirse atada por el franquismo: recordemos la condena de la Dictadura franquista por el Parlamento en la primera legislatura de Aznar -que nunca antes se había producido- o los intentos -más o menos torpes- de recuperación de Azaña como patrimonio común. Aunque a resultas de todo aquello, terminó si cabe más atada que antes al pasado franquista, en parte por la reacción que acompañó aquellos intentos entre sus propias bases sociológicas, en parte por la sensación de impostura que tuvieron las ajenas. La falta de complejos los condujo a confundirse internamente en su relación con el pasado, unido a una ignorancia un tanto naif del mismo, propia de unos dirigentes criados políticamente en la Transición y en la democracia que parecieron creer de verdad la amalgama de interpretaciones ingenuas promovidas entre todos sobre la guerra y sus consecuencias, sus mitos y sus personajes. De algún modo aquel intento de la derecha -tímido pero reconocible- de liberarse del secuestro de su pasado por el franquismo no sólo fracasó sino que despertó viejos fantasmas que

4. Semprún, Jorge, Autobiografía de Federico Sánchez, Barcelona, Planeta, 1976. 
nunca habían desaparecido, entre los propios y entre los ajenos. De hecho, cuando la izquierda sociológica transitó entonces, después de 1996, por los mismos caminos que la derecha en el poder estaba abriendo, pero incorporando su propia coherencia y su propia memoria (parcial, por lo tanto también), la derecha se revolvió en defensa de su ginea franquista, cometiendo el peor error: el del desconocimiento. Pues sólo en la ignorancia se basaba también su intento de crítica de la Dictadura y reivindicación de la democracia republicana en la persona de Azaña. La reacción del franquismo sociológico está perfectamente representada en los abundantes lectores de Pío Moa, que superan a los de cualquier historiador académico o, si me apuran, a los de todos juntos, entre otras cosas porque esa versión negacionista tiene fundamento social y político, educativo e informativo en el franquismo sociológico como hemos indicado en un trabajo reciente ${ }^{5}$. La reacción del antifranquismo sociológico desató las ansias de recuperación de lo que pasa a popularizarse como memoria histórica.

Llegados a este punto y una década más tarde, lo cierto es que la versión de la democracia (que no la de la izquierda) sobre la guerra y la dictadura no está ni empezada a construir. Consensuarla será difícil sino imposible, como corresponde a la historia de una guerra civil pero en todo caso no podemos abdicar de su formulación e intento de construcción. Para hacer avanzar otra construcción del pasado necesitamos dotarnos, como historiadores, de libertad de información y de construcción de hipótesis, de información y de datos. De ahí la reivindicación de la independencia del historiador de oficio y de la necesidad de acumular información antes de interpretación, utilizando las fuentes disponibles y revisando las ya usadas, partiendo de puntos de vista inéditos y, sobre todo, superando la lectura antifranquista como fundamento único de la construcción de la historiografía. Sobra historia militante y guerracivilista en clave de los años treinta y falta de reinterpretación desde los valores de la democracia y los derechos humanos, si bien deben reconocerse los avances en los últimos años en este camino ${ }^{6}$. Carece de sentido la historiografía militante. El franquismo ya no requiere de ser denigrado pues todos los referentes del presente se encargan de hacerlo, en virtud de los valores de democracia y derechos humanos en que se educaron las generaciones actuales.

Pero precisamos comprender sus lógicas y orígenes. Para comprender por ejemplo las consecuencias de que perdure aquella perversión jurídica que el propio Serrano Súñer llamó justicia al revés que sigue vigente y que explica, pri-

5. Fernández Prieto, L., Facendo historia con memoria, Santiago, Ed. 3C3, 2009.

6. Entre otros, los trabajos de I. Saz, J. Rodrigo, J. Ugarte o G. Ranzato, por poner sólo algunos ejemplos, si bien diferentes y aún aparentemente contradictorios entre sí, apuntan en esta dirección. 
mero la tardanza de que un juez español se atreviese con el franquismo, después de que jueces y fiscales españoles, no sólo Garzón, se ocupasen de los crímenes de Chile, Argentina o Bosnia. Y después que, cuando por fin se decide a encausar los crímenes de la guerra y el franquismo, no sólo no fructifique su causa sino que él mismo acabe siendo encausado. Del mismo modo que cuando todo empezó en el verano del 36 y con la misma lógica... y por ventura con otras consecuencias y resultados.

\section{Desde la literatura y el cine, evolución reciente de las visiones de la socie- dad sobre el pasado incómodo}

A veces, frecuentemente, la literatura o el cine permiten ayudar a entender mejor las visiones que las sociedades tienen en el presente sobre el pasado, cómo conciben lo pasado y cómo esta concepción va cambiando. Muchas veces la visión literaria, como ocurre con el señalado caso de Kafka, antecede o anuncia posiciones o ideas que más tarde se materializarán o fenómenos y posibilidades que pasarán a ser normales o cotidianas. La literatura y el cine pueden servirnos de guía en este caso para entender la posición de la sociedad española sobre el pasado incómodo/oculto y ocultado previamente por la propia sociedad y para atender a la evolución reciente de la visión de la represión y la guerra en ambas artes.

Lo que quiero exponer es cómo en la última década, literatura y cine transitaron desde la visión del buen samaritano a la de ¿qué hizo nuestro abuelo? La primera responde a una sociedad que empezaba a «recordar» y a preocuparse por los aspectos menos amables de un pasado conocido pero seguía prefiriendo agarrarse a la mejor visión, la de la buena acción, la del perdón frente a la de la ejecución, la de los salvados frente a los ejecutados. La de la buena acción humanizadora en medio de un horror reconocible en el relato. Se reconocía la muerte -no la singular de un poeta como Lorca (metáfora de aquel engaño en estos días)- injusta e inexplicable, descarnada y que recuerda el genocidio de novelas o filmes no españoles (Hollywood es un gran propagandista de los derechos humanos y la noción de genocidio -aunque también de lo contrario, claro-). Pero se opta todavía por explicar la excepción: la acción del buen samaritano -o del asesino- que evita el asesinato. Es el relato de Manuel Rivas en O lapis do carpinteiro (El Lápiz del carpintero) (1998) para el guardia civil del bando nacional e idéntica visión nos ofrece en Soldados de Salamina J. Cercas (2001), para el miliciano republicano, ambas novelas, no por acaso, llevadas al cine con gran éxito.

Pero conforme avanza socialmente eso que se denomina recuperación de la memoria histórica, se abre camino social e intelectual (historiográfico) una nueva visión, un nuevo punto de vista, más próximo a la verdad más incómoda. Tanto en otro autor gallego S. de Toro, con Home sen Nome (Hombre sin nom- 
bre) como en Almudena Grandes con El corazón helado. Ambos se plantean el problema del verdugo y asumen la incomodidad de una sociedad en la que unos mataron a otros en un momento determinado. Desde el presente, los hijos o los nietos han de enfrentarse con el pasado de sus padres o abuelos.

El tránsito de una a otra visión está relacionado con el mayor y profundo conocimiento de la violencia ejercida, su crudeza y extensión, y la comparación con procesos genocidas europeos de entreguerras, con el revival de la guerra de Bosnia, o de los casos de las dictaduras latinoamericanas, con sus secuelas en forma de procesos judiciales de los que participa incluso la judicatura española. La fosas de Sbrenica y la búsqueda de sus responsables o las matanzas de Ruanda son un mazazo a nuestro pasado incómodo. Y en todo caso se trata de una tendencia universal en sociedades que todavía no se han enfrentado a su pasado incómodo; recientemente $\mathrm{H}$. Mankell en El retorno del profesor de Baile (2005), se plantea la misma cuestión: ¿qué hizo mi padre?, ¿fue un nazi en el tiempo de los nazis?

Antes del tránsito señalado (1995) en A lingua das bolboretas (La lengua de las mariposas) un cuento del libro Que me queres amor?, M. Rivas se aproxima, de una forma que nadie había hecho antes, hasta el borde del problema, pero no más allá, para explicar porqué la sociedad atemorizada crucifica al que antes santificaba, en la despedida del maestro D. Gregorio, (Traidores!, criminales!, rojos!, gritan los vecinos del maestro) al que insultan sus alumnos, animados por sus padres (Bérralle ti tamén Monchiño:,... sapoconcho! Tilonorrinco!, iris!) cuando con otros presos sube al camión de incierto destino. D. Gregorio es un transunto de D. Gregorio Sanz, un maestro de Ribadeo, autor en 1986 de una de esas memorias editadas por Edicións do Castro y tituladas Uno de tantos. Cinco años a la sombra, en las que cuenta su detención y encarcelamiento, pero no cuenta todo lo que pasó ni con certeza todo lo que sabía y todo lo que se sabía en el pueblo. Cincuenta años olvidando no facilitaban las cosas. Pero todos lo sabían aunque él no lo contase. Por algo la primera corporación democrática de 1979 le dio su nombre al grupo escolar de la villa.

\section{Fases de recuperación de la memoria de la Guerra Civil y del franquismo desde 1975 hasta hoy}

Antes y después de estas novelas se desarrolla ese proceso denominado de recuperación de la memoria histórica. Un ensayo sumario sobre la forma y las fases por las que pasa el ansia de conocer y reconocer en las últimas siete décadas lo acontecido en la guerra, los ámbitos en que se desarrolla y los caminos por los que transita puede ser de interés para evidenciar los círculos concéntricos en que se movió. 
Durante la Dictadura el conocimiento de lo ocurrido estuvo oculto y restringido en el ámbito individual o privadamente familiar, soportado en un recuerdo muchas veces penoso, no pocas avergonzado y siempre parcializado.

1975-1996:

La memoria de la Guerra Civil y del franquismo prevalece y se renueva dentro de las familias. Se trata de una memoria ocultada -lo que no quiere decir olvidada-. Es una memoria fragmentaria con ciertas repercusiones en la esfera pública, por ejemplo en libros y películas que tratan el tema. Y acompañada de numerosas publicaciones periodísticas o históricas (investigaciones sobre el franquismo o la represión) en los primeros años de la Transición que se suman a los trabajos de exiliados e hispanistas publicados ahora libremente en España. Pero apenas hay actuaciones que puedan destacarse como políticas públicas de memoria.

Desde 1996:

La memoria de la Guerra Civil y del franquismo pasa de la memoria de las familias al debate social. Este paso se explica por la reacción de los nietos, por la necesidad de ir en contra de las políticas de la historia del PP y también está motivado por la forma en que resuelven otros países la salida de sus dictaduras (Argentina, Chile, Sudáfrica). Este paso al ámbito social está visible en la creación de la Asociación para la recuperación de la memoria histórica (Emilio Silva y Santiago Macias). Muchas otras asociaciones que se dedican a una tarea semejante aparecen en los años siguientes.

Desde 2000:

La memoria de la Guerra Civil y del franquismo pasa a la política y al debate político, acompañando a ese creciente debate social.

Desde 2004:

Con el cambio de Gobierno, el fin de recuperar la memoria histórica de la Guerra Civil y del franquismo se instala en el poder ejecutivo. Por ejemplo, se proclama el año 2006 como «año de la memoria». En Galicia, se declara la misma medida aún más temprano, ya en 2005, también con el cambio de Gobierno.

Paralelamente se traslada al ámbito legislativo con la preparación, debate y aprobación de la denominada Ley de la Memoria Histórica que concreta la aplicación de políticas públicas de la memoria.

En 2008, llega por vez primera al ámbito judicial con el auto del juez Garzón pero con los resultados conocidos porque la denominada Ley de la Memoria Histórica no anula los juicios franquistas.

Vayamos pues con la orientación y el sentido de las políticas públicas de la memoria que se aplicaron en Galicia así como el contexto de las mismas y finalmente algunos de los resultados del programa de investigación que estamos desarrollando. 


\section{Antes y después de las políticas públicas}

La recuperación de la memoria de la Guerra Civil en Galicia fue en su inicio bastante ajena a la política. El conocimiento de ese pasado oculto fue bastante anterior al reconocimiento de las víctimas y estuvo en primera instancia en manos de investigadores aislados, y en muchas ocasiones autodidactas, o bien se concretó en trabajos académicos en los años noventa ${ }^{7}$. Al mismo tiempo hay que reseñar la colección Documentos para a Historia Contemporánea de Galicia de Ediciós do Castro, en la que el editor Isaac Díaz Pardo publicó desde comienzos de los años ochenta decenas de testimonios de protagonistas de la represión y el exilio hasta constituir un amplio corpus de gran utilidad para los historiadores.

A finales de los años noventa tuvieron lugar, en Tui y Ribadeo, los primeros homenajes públicos debidos a iniciativas sociales e intelectuales locales apoyadas en ambos casos por organizaciones del nacionalismo. En ambos extremos del país gallego, en el verano de 1999 se llevaron a cabo sendos homenajes a las víctimas de la represión que pasan por ser los primeros. En Tui se concretó, además, en la inauguración de un monumento a los numerosos fusilados en aquella localidad, la última de Galicia en caer en manos de los rebeldes en julio de 1936. A partir de entonces se fueron sumando iniciativas a cuentagotas. Sobre la Islaprisión de San Simón, la isla de de los presos, y con un trabajo previo de muchos años, se edita el documental Aillados (2000) y al año siguiente en Redondela y A Coruña (en $O$ campo da Rata) se inauguran sendos monumentos dedicados a la memoria de los represaliados, promovidos por corporaciones socialistas ${ }^{8}$.

7. Wouters, M., 1936: Os primeiros días, Vigo, Xerais, 1993; Souto Blanco, M. J., La Represión franquista en la provincia de Lugo (1936-1940), Sada, Ediciós do Castro, 1998; PRADA Rodríguez, J., Ourense, 1936-1939. Alzamento, guerra e represión, Sada, Ediciós do Castro, 2004 o los de Lamela García, V. Luis, "Foucellas», el riguroso relato de una lucha antifranquista, (1936-1952), Sada, Ediciós do Castro, 1992, Crónica de una represión en la «Costa da Morte»: Cée, Vimianzo, Ponte do Porto, Corcubión, Fisterra, Zas, Sada, Ediciós do Castro, 1995, Estampas da injusticia : la guerra civil del 36 en A Coruñ y los documentos originados en la represión, Sada, Ediciós do Castro, 1998 entre otros más recientes. Antes de esa fecha hay que consignar los trabajos de C. Fernández y B. Máiz sobre la Guerra Civil: Fernández, Carlos, El Alzamiento de 1936 en Galicia: Datos para una historia de la Guerra civil, Sada, Ediciós do Castro, 1982 y Márz Vázquez, Bernardo, Galicia na Segunda República e baixo o Franquismo: 1930-1976, Vigo, Xerais, 1988 y una especial atención a la guerrilla antifranquista y el fenómeno de los fuxidos por parte de historiadores como H. Heine y Carlos Reigosa: Heine, H., A guerrilla antifranquista en Galicia, Vigo, Xerais, 1980 y sobre todo de periodistas como V. Freixanes, Freixanes, V., O Fresco. Memorias dun fuxido, Vigo, Xerais, 1981 y Reigosa, Carlos G., Fuxidos de sona, Vigo, Xerais, 1989, ampliado y reeditado en 2003.

8. Aunque ya en 1976 exiliados del PSOE retornados habían colocado una placa en el Cementerio Civil en recuerdo de los fusilados y años más tarde el alcalde socialista homenajeó al alcalde republicano de la ciudad fusilado en 1936 y actos de este tipo menudearon 
La creación de colectivos sociales de recuperación y/o reivindicación de la memoria se inicia con el cambio de siglo y con apoyo municipal se celebran desde 2002 sucesivos Congresos en Narón primero y Cambre después, sobre la Memoria y la represión que reúnen principalmente a investigadores y colectivos ciudadanos. En 2004 se celebra en Santiago y Ourense el Congreso de la Asociación de Historia Contemporánea bajo el título Memoria e Identidades.

Las iniciativas se suceden desde entonces pero no será hasta el cambio de Gobierno del verano del 2005, fecha en que el ejecutivo bipartito de PSOE y BNG sustituye en la Xunta de Galicia a Manuel Fraga, cuando se inicie una auténtica política de la memoria en el país. En septiembre de ese año el Gobierno gallego, a instancias de la Consellería de Cultura e Deporte, declara el 2006 como Ano da Memoria9 . En línea con esa denominada recuperación de la memoria histórica y reconocimiento de las víctimas, común a todo el Estado desde finales de los años 90, en Galicia contiene un plus innegable relacionado con el ambiente de liberación que supone el cambio de Gobierno pues, después de 70 años de continuidad, salvo los dos años de gobierno tripartito a finales de los ochenta, nunca desde 1936 volvió a gobernar la izquierda o el nacionalismo en Galicia. Gobiernan ahora la autonomía los herederos políticos de la República y, por lo tanto, también los herederos, política y personalmente, de los asesinados en el 36. Es decir, los que se reclaman política y personalmente herederos de los represaliados, porque herederos hay muchos más, tanto personales como familiares. Y ello apunta a una de las características de la represión y sus consecuencias en Galicia a la que después aludiremos.

Desde el verano de 2005 se realizan los primeros homenajes públicos con apoyo del Gobierno gallego, que vuelven a tener como escenario la Illa de San Simón, convertida en catalizador de la conmemoración del Ano da Memoria y es en ella donde la Consellería de Cultura llevó a cabo el homenaje a los represaliados por la dictadura franquista en julio de 2006. Posteriormente se realizaron exposiciones como «A Illa da Memoria. A represión no cárcere da Illa de San Simón (1936-1943)», Memorial da Liberdade sobre la represión franquista y la resistencia democrática en Galicia o la experiencia del Barco da Memoria: el viejo vapor «Hydria II» recorrió los puertos de la fachada atlántica y sirvió de contenedor de la exposición «Os Mártires do Mar» sobre la represión de los sublevados contra las gentes del mar. Paralelamente se asiste a la creación de numerosas asociacio-

también en Ferrol y otras ciudades con los primeros gobiernos municipales democráticos de 1979.

9. Avanzado el año 2006 también el Gobierno del Estado hará suya esta Declaración de Año de la Memoria. 
nes que tienen por objetivo la recuperación y reivindicación de la memoria de las víctimas ${ }^{10}$.

Ya a finales del 2005 se concibe el Proyecto de Investigación «As vítimas, os nomes e as voces» que fue sometido a un debate público y presentado en sucesivas reuniones con colectivos e investigadores interesados. Las iniciativas políticas promovidas desde la Xunta de Galicia, abarcan por otra parte un abanico más amplio de las que puede hacerse ahora un sucinto repaso: creación del Consello da Memoria, con representación de asociaciones, personalidades supervivientes como Isaac Díaz Pardo y Avelino Pousa Antelo, familiares de víctimas, historiadores e investigadores sobre la represión; una convocatoria pública de ayudas en 2006, 2007 y 2008 para la realización por parte de asociaciones y particulares de actividades de investigación, homenajes, audiovisuales ${ }^{11}$; homenajes a las víctimas de la represión en San Simón, a los maestros y maestras represaliados, a las mujeres. Otras instituciones se sumaron a la marea conmemorativa: el Parlamento gallego rindió homenaje a los gallegos que perecieron en los campos de concentración nazis y a los diputados asesinados y la Universidade de Santiago celebró en 2006 un acto académico en honor del personal, estudiantes y profesorado depurado en 1936 (el 40\% de los catedráticos y el 27\% de todo el profesorado) ${ }^{12}$; la Deputación de Ourense (gobernada por el PP) se sumó también a estas iniciativas, incluyendo en su Web los nombres de los asesinados en la provincia ${ }^{13}$.

Especialmente relevante en esta apertura pública al pasado incómodo resultó la liberación de las memorias y los recuerdos que habían permanecido ocultos, en unos casos, ignorados en otros. Se extendió la sensación de que «ahora ya se puede contar lo que pasó» y de ello se benefició ampliamente nuestro proyecto de investigación: aparecieron recuerdos, materiales, fotografías, publicaciones e incluso un buen número de memorias manuscritas ${ }^{14}$. Aquellos

10. En la página web, www.nomesevoces.com, se puede acceder a las direcciones de la mayoría de estas asociaciones.

11. Ayudas de las que quedaron expresamente excluidas actividades como la exhumación de fosas o la colocación de placas que quedó a iniciativa de la sociedad civil.

12. El 14 de marzo de 2006 en el Paraninfo de la Universidade de Santiago de Compostela y previamente había retirado a Franco del libro de Doctores Honoris Causa.

13. Los datos, resultado de un proyecto de investigación desarrollado por profesores del Departamento de Historia del Campus de Ourense (Universidade de Vigo) como Xulio Prada y Jesús de Juana, pueden ser consultados en http://www.depourense.es/represion/.

14. En alguna ocasión incluso de padres de militantes antifranquistas que los habían ocultado a sus propios hijos hasta la actualidad. Entre la documentación recompilada, destacamos las copias de una agenda de Aquilino Sánchez Rodríguez, alcalde de O Carballiño, en la que recoge algunos datos sobre la situación del ayuntamiento en los primeros momentos de la sublevación y narra sintéticamente su detención e ingreso en prisión; las memorias 
recuerdos dejaron de ser las «batallitas del abuelo» o «la vergüenza de la familia» para adquirir un valor que, en no pocas veces, se transforma en orgullo. Se naturaliza, se expresa, el recuerdo oculto o privado, no pocas veces rencoroso, con frecuencia reivindicativo e incluso en ocasiones vengativo. El recuerdo es tan convulso que en dos ocasiones ha terminado en los juzgados de Cambados y A Estrada.

La declaración de 2006 como Ano da Memoria por parte del Gobierno gallego y las iniciativas de la Consellería de Cultura y de la sociedad civil que la siguieron desvelaron nuevos fragmentos de un pasado oscurecido, favorecieron su conocimiento y sobre todo el de las víctimas en el espacio público que todavía les era ajeno. Se le dio valor al recuerdo oculto y privado y ello permitió naturalizar, expresar, lo que siempre se había silenciado. Las experiencias de los abuelos alcanzaron así otra dimensión y fueron por fin reivindicadas, la mayoría de las veces por los nietos y también por los hijos que se sienten reconocidos después de padecer décadas de negación. Las víctimas no hablan si no se les da la oportunidad, y esto es lo que intentamos hacer desde el Proyecto de Investigación aprovechando el nuevo clima creado. En ese contexto de recuperación las memorias privadas aspiran a hacerse públicas y los testimonios que hasta el momento hemos recogido ocultan formas muy variadas de exclusión a lo largo de los últimos setenta años: de la orfandad a la destrucción de las trayectorias profesionales, de la cárcel a la invisibilidad, o por decirlo mejor, al intento de ocultación. Al lado de la memoria franquista triunfante en el imaginario político y popular, aunque oculta también en el período democrático, aparecen pues otras memorias que, evidentemente, requieren del necesario análisis crítico para su aprovechamiento historiográfico.

Esta recuperación de memorias está en disposición de convertirse por fin en Historia construida por los historiadores. En conjunto se trata de memorias que entran en conflicto con la del franquismo, con la construida durante la Dictadura, que es todavía la Historia conocida y pública, la única versión y todavía la versión predominante. La pervivencia de la Historia de la guerra fraguada y construida en el franquismo sigue siendo todavía hoy el marco de referencia preferente ${ }^{15}$.

de un marinero que fue militante del sindicato «Solidaridad Marinera» de Moaña, Luís Pérez; las memorias del cerdedense Rogelio Arca Rivas, en las que relata la participación de numerosos canteros de Terra de Montes en las unidades del Ejército Popular de la República en la zona Centro; el diario de cárcel de Eusebio Cuesta, líder socialista monfortino o los escritos de un «topo» que permaneció durante la Dictadura escondido en su casa de As Nogais (Lugo).

15. A este respecto vid. Fernández Prieto, L. (coord.), «Memoria do 36», Grial, 170 (2006). 
Antes de la aparición de las políticas públicas de la memoria sólo hubo silencio y pasado, y realmente poca Historia. En el conjunto del Estado se hizo mucha política con la memoria pero poca política de la memoria. ¿Y cómo es recibido este aluvión de memoria en Galicia, incluida la aplicación de la Ley de la Memoria Histórica? Unos pocos datos pueden servir de referencia.

En A Coruña, con Gobierno de coalición socialista y nacionalista, el viejo callejero sigue siendo el del cementerio civil, demócratas y liberales de antes de la Guerra Civil, alcaldes como Linares Rivas, poetas como Curros Enríquez o mujeres liberales y liberadas del XIX como Juana de Vega, que comparten el espacio urbano con golpistas como el general Sanjurjo; el cambio de denominación del Hospital Universitario de la ciudad, Juan Canalejo, en honor a un líder de la Falange local se ha ultimado recientemente, no sin problemas, y la derecha local ha convertido la defensa de la permanencia de la estatua de Millán Astray en un bastión. En su argumentario la propuesta de colocar al lado otra de Unamuno como símbolo de la «reconciliación», refleja una confusión mental sobre el pasado que no puede pasar desapercibida.

En todo caso la actitud del PP es ambivalente. Por un lado mantiene en Galicia el discurso homogéneo y ortodoxo del conjunto del Estado y así la alcaldesa del PP de Vigo se negó a entregar en 2006 la medalla de la ciudad a la Asociación Memoria do 36, concedida por la mayoría del Pleno (BNG-PSOE), aduciendo argumentos supuestamente legales. Sin embargo en el Parlamento gallego, el PP votó con los demás grupos una moción para la aplicación de la Ley de la Memoria Histórica en Galicia que instaba, entre otras cosas, a la exhumación de fosas. Y como ya se señaló, la Deputación de Ourense pagó y publicitó un estudio sobre la represión en esa provincia. También nos consta directamente la colaboración con el Proyecto de Investigación de concejales del PP.

Entre los profesores que recibieron el Homenaje celebrado en la Universidad de Santiago en 2006 se encontraba Enrique Rajoy Leloup, abuelo del actual líder del PP, alguno de cuyos descendientes directos estaban presentes y recogieron la medalla conmemorativa. Del conjunto de familiares directos de los represaliados que fueron invitados otros dos descendientes también declinaron participar aunque transmitieron su agradecimiento. 


\section{El Proxecto de Investigación Interuniversitario «As vítimas, os nomes e as voces» ${ }^{16}$}

En abril de 2006 las Universidades de Santiago de Compostela, Vigo y A Coruña, firmaron con la Consellería de Cultura e Deporte de la Xunta de Galicia un convenio de colaboración para llevar a cabo un programa de investigación sobre la Guerra Civil y la represión en Galicia. El programa nació dentro de las iniciativas de la declaración institucional del 2006 como Ano da Memoria y con vocación de continuidad. Desde su inicio, pretendió establecer una colaboración con asociaciones y particulares que en Galicia trabajaron y trabajan por la recuperación de la memoria de la represión franquista. El objetivo central es el de recopilar información para la creación del futuro centro de la memoria sobre la Guerra Civil y el franquismo, llamado a convertirse en un espacio de estudio e indagación permanente, pero también de información y divulgación, en una triple vertiente de investigación, documentación e interpretación.

En la definición del proyecto optamos por ocuparnos exclusivamente de las víctimas y no de los victimarios, asumiendo las razones que ya fueron expuestas de modo general al inicio de este artículo. Entre los planteamientos de partida nos proponemos contrastar el mito de la adhesión de Galicia al Alzamiento (golpe de Estado), cultivado por el franquismo y asumido con inercia argumental social y políticamente hasta el presente de modo general. Queríamos también definir la tipología de la represión e indagar en la lógica de la violencia desatada con el golpe de Estado de julio de 1936; valorar la continuidad política con el franquismo en Galicia en relación con la memoria de la represión; ponderar la profundidad de la ruptura con el exilio y la República que se produce en el país durante las cuatro décadas de la Dictadura. Por último desentrañar el contexto en el que se genera una violencia que se produce en una única dirección, pues no existe, dadas las conocidas condiciones del triunfo del golpe en Galicia, ni represión contra los golpistas ni proceso revolucionario.

La pervivencia de la Historia fraguada y construida durante el franquismo explica en buena medida la pervivencia de tópicos como el de la supuesta adhesión de Galicia al golpe de Estado primero y al régimen franquista después,

16. El equipo está coordinado por los siguientes investigadores: Emilio F. Grandío Seoane en la provincia de A Coruña, M. ${ }^{a}$ Jesús Souto en Lugo, Julio Prada en Ourense, Dionisio Pereira en Pontevedra, Xurxo Pantaleón es responsable técnico de Fuentes Orales y Xosé Manoel Núñez Seixas el de la Galicia Exterior. Como investigadores se encuentran Andrés Domínguez Almansa, Gustavo Hervella García y Antonio Somoza Cayado. Responsable de relaciones externas y comunicación: Chus Martínez Domínguez. Además en el proyecto han trabajado como investigadores durante dos años, Eva Vieites Salmonte, Mónica Rocha Novoa y Antonio Míguez Macho. 
porque se arrebató la memoria e incluso la posibilidad de recuperarla. En términos históricos, y comparando el contexto histórico de 1936 y el actual de recuperación de la memoria, es necesario explicar dos paradojas que contradicen la versión oficial sobre la adhesión de Galicia al golpe de Estado. Primero, que apenas dos semanas antes del golpe: el 28 de junio se votó el Referéndum de Autonomía de Galicia por amplísima mayoría y después de una gran campaña de movilización que evidencia el apoyo ciudadano a la República. Segundo, que el triunfo del golpe en Galicia exigió el fusilamiento de todas las autoridades militares de la región militar y de todas sus plazas, incluido el Arsenal de Ferrol. Los datos de la realidad parecen negar una conjetura políticamente construida que, en todo caso, debe ser demostrable y no sólo opinable.

A aportar información para clarificar estas u otras hipótesis se orienta también el programa de investigación emprendido en 2005 que, además de recuperar información en trance de perderse, tiene como objetivo contribuir a construir la historia de la guerra y el franquismo. De convertir, pues, la memoria en Historia, con la recuperación de datos y materiales que puedan ser después sometidos al necesario tratamiento crítico. Es necesario explicitar, incluso advertir, que no guía al proyecto el objetivo de hacer una supuesta historia antifranquista. No sería un punto de partida aceptable metodológicamente pero además es innecesario, pues el empeño de la destrucción de la democracia republicana y el propio desarrollo de la dictadura franquista se descalifican por sí mismas mediante el conocimiento histórico desde los valores (humanos y democráticos) del presente. El moralismo, además de tramposo es superfluo para hacer historia si fluye el conocimiento informado. Y de eso se trata. Dado el grado de desconocimiento y desinformación sobre muchos aspectos de este pasado, podríamos afirmar que en cierto modo estamos todavía en la fase de una reconstrucción positiva del pasado y para ello es preciso el acarreo de las fuentes y las informaciones precisas, desde los presupuestos de partida señalados. La deconstrucción de los tópicos franquista, es por cierto uno de ellos.

El proyecto centra pues los esfuerzos en el estudio de la represión y la violencia vinculada al golpe de Estado y la construcción del régimen franquista. Contra la idea frecuentemente repetida sobre una represión que se concentra principalmente en sectores populares, los datos disponibles indican que estuvo dirigida en realidad contra las elites de la democracia y de la sociedad republicana en Galicia. Elites políticas: gobernadores civiles, presidentes de Diputación, diputados, alcaldes, concejales, dirigentes de partidos democráticos; contra las elites intelectuales: maestros, profesores de Universidad, científicos, artistas; contra las elites de una sociedad plural democrática y sus cuadros sociales y sindicales: militantes, dirigentes de sociedades agrarias, círculos y ateneos obreros, 
organizaciones de mujeres; contra las elites profesionales: abogados, médicos, arquitectos, jefes de Correos, altos cuadros de la Administración. Esta diversidad que indicaban ya los trabajos previos, es la que se quiere recoger por parte del Proyecto de Investigación «As vítimas, os nomes e as voces», con las dificultades del paso del tiempo y de la localización de los protagonistas.

Se analizan también las diversas formas de represión, del asesinato hasta las más capilares y sutiles, derivadas de la violencia generada. Al lado de los muertos, y en una relación conocida que no quiere ni puede ser exhaustiva, están los que sufren la cárcel, los depurados de empleos públicos, los despedidos de sus puestos de trabajo, los multados e incautados que pierden sus propiedades, los que son continuadamente amenazados, perseguidos y vigilados, aunque nunca entrasen en la cárcel. Las mujeres violadas, rapadas y embarazadas. Los que quedan marcados de por vida y a los que siempre se les recuerda su marca de apestados para que nadie se mezcle con ellos. Las entrevistas realizadas reúnen testimonios plurales y diversos en este sentido. Los protagonistas que padecieron en primer término la represión cuentan como era la vida en la prisión, en los calabozos improvisados en conventos, colegios o casas particulares. Sus hijos, estigmatizados como «hijos de rojos», cuentan cómo pudieron vivir los cuarenta años de dictadura y el saberse señalados por las autoridades.

\section{La construcción de un fondo oral}

Recoger el relato de los protagonistas es una de las tareas principales del Proxecto de Investigación; esto supone la creación de fuentes orales para el estudio de un período en el que las fuentes escritas son escasas y atienden a la lógica de la represión, por lo que los relatos de las víctimas y sus descendientes permiten obtener otro punto de vista de contraste para completar el cuadro. A partir de los datos conocidos, y siguiendo una metodología desarrollada en los últimos veinte años en el equipo Historga, desarrollamos el programa de entrevistas, sobre cuestionarios abiertos que intentan indagar en las formas y características de la represión pero también en el perfil de los represaliados o las condiciones previas de violencia y conflictividad, anteriores a julio de $1936^{17}$.

\section{Creación de una base de datos de víctimas}

Un objetivo motor del proyecto es elaborar una relación de nombres de las víctimas de la represión en Galicia en el período de la Guerra Civil (1936-1939).

17. El equipo Historga ha acumulado en estas dos décadas en torno a 400 entrevistas sobre la Guerra Civil y la represión que permiten unas bases de partida informadas y solventes para el actual proyecto. 
Para sistematizar la información obtenida de las distintas fuentes empleadas en la investigación, se construye una base de datos que recoge los nombres y la trayectoria de los afectados. La base de datos está construida en torno a las siguientes fuentes documentales:

-Causas de los Tribunales Militares de Tierra y de Marina de la Región Militar a la que se encuentra adscrita Galicia, con base en Ferrol.

-Libros de defunciones de los registros civiles de los ayuntamientos de Galicia ${ }^{18}$.

-Una selección bibliográfica de trabajos y publicaciones sobre la represión que aportan nombres de represaliados/as.

-Vaciado de las fuentes hemerográficas existentes para los años de la Guerra Civil y los primeros de la dictadura.

Cuadro 1. Número de causas revisadas y vaciadas de las plazas militares de tierra de Galicia. (1936-1939) ${ }^{19}$

\begin{tabular}{|c|c|}
\hline PLAZA & CAUSAS VACIADAS \\
\hline A Coruña & 306 \\
\hline Ferrol & 98 \\
\hline Lugo & 378 \\
\hline Ourense & 351 \\
\hline Pontevedra & 235 \\
\hline Santiago de Compostela & 143 \\
\hline Vigo & 279 \\
\hline Total & 2.615 \\
\hline
\end{tabular}

Fuente: Elaboración a partir de los datos del proyecto de Investigación «As vítimas, os nomes e as voces».

18. Las cifras de muertos inscritos en el registro civil de defunciones para las principales ciudades de Galicia en el período 1936-1939 son:

A Coruña: 265; Lugo: 181; Ourense + Canedo: 40; Pontevedra: 181; Compostela + Enfesta: 94; Ferrol + Serantes: 541 y Vigo + Lavadores + Bouzas: 400.

Para la ciudad de Ourense se contabilizan exclusivamente los muertos inscritos en el registro civil de defunciones, es decir, los fusilados en la plaza militar al aparecer reseñados en la causa correspondiente ya no se recogieron en la fuente judicial civil.

19. A esta cifra hay que sumar las causas militares del Archivo de Marina de Ferrol para el mismo período: 824 causas revisadas (2.986 procesados). Actualmente se está procediendo a recopilar los inculpados no procesados. Los datos provisionales son: Plaza de FerrolMarina, 2.986 procesados y 1.249 encausados no procesados; plaza de Ourense, 1.345 procesados y 666 encausados no procesados. 
A mayores de estos fondos, desde el Proyecto de Investigación se pretende realizar una búsqueda en otras fuentes documentales: Libros-registro de prisiones para cuantificar e identificar presos gubernativos sin más rastro documental, registros sanitarios en los que se podrán consultar las fichas de mortalidad para cuantificar y validar la represión con resultado de muerte; prensa y publicaciones periódicas de aquellos años, importantes a la hora de conocer asesinatos y medidas represivas de carácter económico y profesional.

\section{Presentación de resultados provisionales}

En los anexos se presenta la ficha de víctimas, para comprobar la estructura y contenidos de la información recopilada por el proyecto. Pero queremos avanzar aquí algunos de los resultados provisionales y un breve análisis de los mismos. La presentación es tan sumaria como el análisis, pendiente de una adecuada evaluación.

Los datos de las víctimas contabilizadas de la represión para el período 19361939, obtenidas a través del vaciado de las fuentes y depuradas hasta garantizar su validación última, con todas las garantías que entendemos son requeridas, ofrecen un panorama de la represión como un proceso más complejo y diverso de lo esperado. El objetivo del proyecto no es la mera contabilización, que en todo caso es importante porque permite determinar por fin una dimensión que hasta el momento sólo era conocida de forma fragmentaria, sino dotarnos de información precisa para adentrarnos en la lógica del exterminio del contrario que es consustancial al golpe de Estado de julio de 1936 y al franquismo como resultado político del resultado de la guerra. Las cifras ofrecidas no recogen todas las formas y la capilaridad de la acción represiva sino exclusivamente el número de asesinados y procesados militarmente entre julio de 1936 y diciembre de 1939. Fuera de ellas quedan muchas otras formas que no tienen reflejo documental, en especial las diversas prácticas de agresión contra las mujeres, pero también detenciones no registradas, palizas y otras formas de vejación y persecución.

El cuadro 2 presenta las víctimas (recogidas en la base de datos en red www. vocesenomes.com) procesadas en juicios militares y asesinadas, previo juicio o sin él y de las que tenemos constancia documental. 
Cuadro 2. Víctimas contabilizadas de la represión franquista en Galicia: procesos y asesinatos (1936-1939)

\begin{tabular}{|c|r|r|r|}
\hline & HOMBRES & MUJERES & TOTAL \\
\hline Procesados/as sin resultado de muerte & 7.007 & 313 & 7.320 \\
\hline Víctimas con resultado de muerte & 4.506 & 85 & 4.591 \\
\hline Total de víctimas & 11.513 & 398 & 11.991 \\
\hline
\end{tabular}

El cuadro 3 reúne a todos los individuos sometidos a procesos militares en las cuatro provincias gallegas y el 4 el conjunto de víctimas de asesinatos en Galicia. Como ya se ha indicado todos los datos se refieren al período julio de 1936 a diciembre de 1939 .

Cuadro 3. Víctimas de la represión en procesos militares en las cuatro provincias de Galicia (1936-1939)

\begin{tabular}{|c|c|c|cc|}
\hline & HOMBRES & MUJERES & \multicolumn{2}{|c|}{ TOTAL $\%$} \\
\hline Procesados no ejecutados & 7.007 & 313 & 7.320 & $84^{\prime} 6 \%$ \\
\hline Penas de muerte ejecutadas & 1.318 & 8 & 1.326 & $15 \% 4 \%$ \\
\hline Total de procesados & 8.325 & 321 & 8.646 & $100 \%$ \\
\hline
\end{tabular}

Cuadro 4. Víctimas de asesinatos en Galicia (1936-1939)

\begin{tabular}{|c|c|c|cc|}
\hline & HOMBRES & MUJERES & \multicolumn{2}{|c|}{ TOTAL \% } \\
\hline Penas de muerte ejecutadas & 1.318 & 8 & 1.326 & $29 \%$ \\
\hline Asesinatos extrajudiciales & 3.188 & 77 & 3.265 & $71 \%$ \\
\hline Total asesinatos & 4.506 & 85 & $4.591 \quad 100 \%$ \\
\hline
\end{tabular}

Fuente: Proyecto de investigación «Nomes e voces».

Una primera conclusión de los datos, completada con los testimonios orales, apuntan a que esta violencia y en especial los asesinatos, con soporte judicial o sin él, constituye una forma de terror que tiene por objetivo imponer y asegurar el golpe militar. La eliminación física del rival político, en cuanto forma de persecución y exterminio, supone una forma de solución del conflicto político propia del tiempo histórico de los fascismos europeos. Procesos y asesinatos buscan no sólo eliminar sino también aterrorizar. Eliminar el poder político, militar y social que podría determinar el fracaso o la reacción frente al golpe y con su carácter ejemplarizante aterrorizar a los que no eran ejecutados. A ello contribuye especialmente la publicidad de los asesinatos y la visión de los asesinados que, sobre 
todo en los primeros meses, serán depositados en las cunetas y encrucijadas de carreteras transitadas. Tiene por lo tanto un objetivo paralizante de cualquier forma de resistencia, incluso más que un castigo de la resistencia que apenas tuvo lugar de forma mínimamente efectiva, salvo en el Arsenal de Ferrol y algunas localidades como Tui.

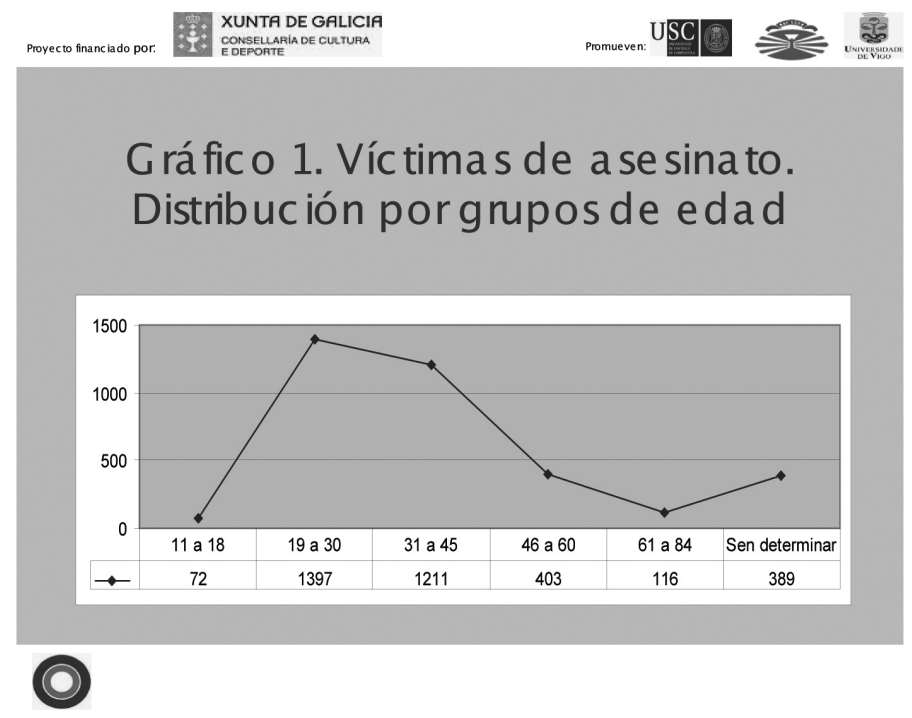

Fuente: Proyecto «Voces e Nomes» ${ }^{20}$.

La distribución por grupos de edad de los asesinados pone en evidencia a la generación que protagoniza y sufre el conflicto. La concentración en los grupos de edad de $19-30$ (38'9\%) y 31 a 45 (33'7\%) del 72'6\% de los asesinados alude además al carácter selectivo de un terror que se concentra en sectores jóvenes y en no pocos casos cuadros con poder político social y sindical o asociativo. El primero de los grupos de edad es, además del que concentra a más eliminados, posiblemente también el que concentre más eliminadores. El franquismo se construirá sobre una nueva generación, la que protagoniza la guerra pero también la que elimina al contrario, lo que puede explicar también, en cierto modo, la longevidad del Régimen y la forma en que el franquismo supera la muerte del Dictador.

20. El gráfico está confeccionado sobre los datos obtenidos por el proyecto a la altura de junio de 2008 y por lo tanto sobre un total de 3.588 asesinados y no sobre el total contabilizado un año más tarde (ver cuadro 3). Nos parece importante presentarlo de todos modos por su carácter representativo. 


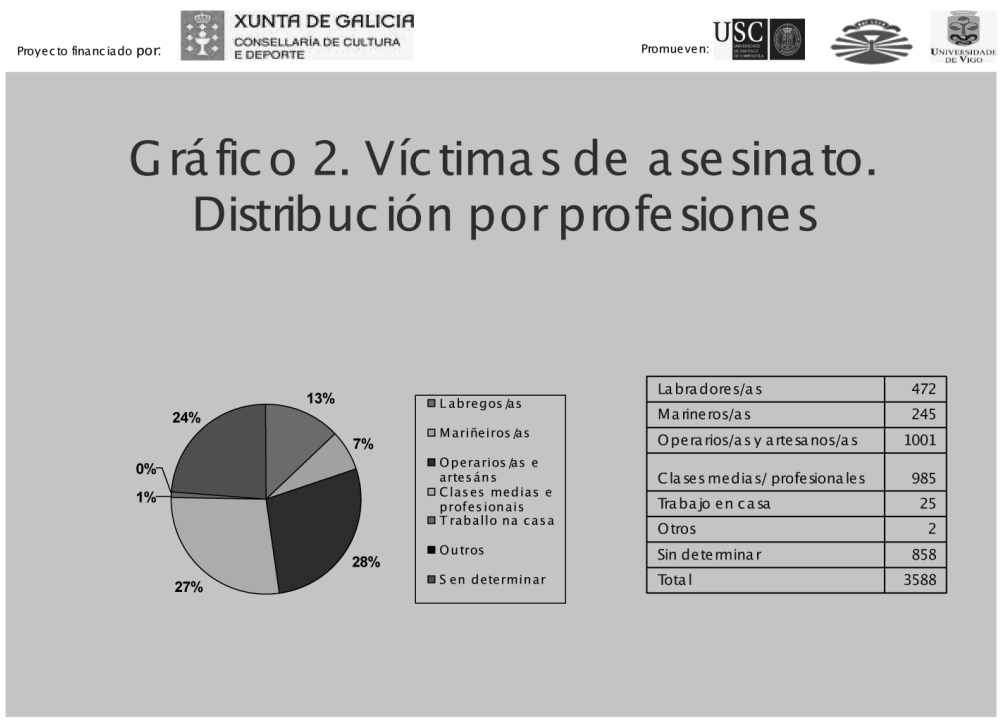

\section{○}

Fuente: Proyecto «Voces e Nomes» 21.

Los datos sobre las profesiones de los asesinados de los que conocemos su dedicación, revelan una distribución casi tripartita. Si descontamos un 24\% de profesión desconocida, el grupo de operarios y artesanos es casi idéntico al de clases medias y profesionales, en el que se incluyen los casi tres centenares de militares y miembros de cuerpos de seguridad ejecutados sumariamente, junto con funcionarios, empleados cualificados, profesionales liberales, pequeños industriales y comerciantes; el grupo de labradores y marineros supone por su parte un significativo 20\% (13 y 7\% respectivamente). Estas cifras han de estar sometidas a la necesaria cautela en su agrupamiento -e incluso identificación-y a futuras contrastaciones pero nos parecen, en su provisionalidad, suficientemente reveladoras de la distribución social de los asesinados en este período.

21. Idem gráfico 1 . 

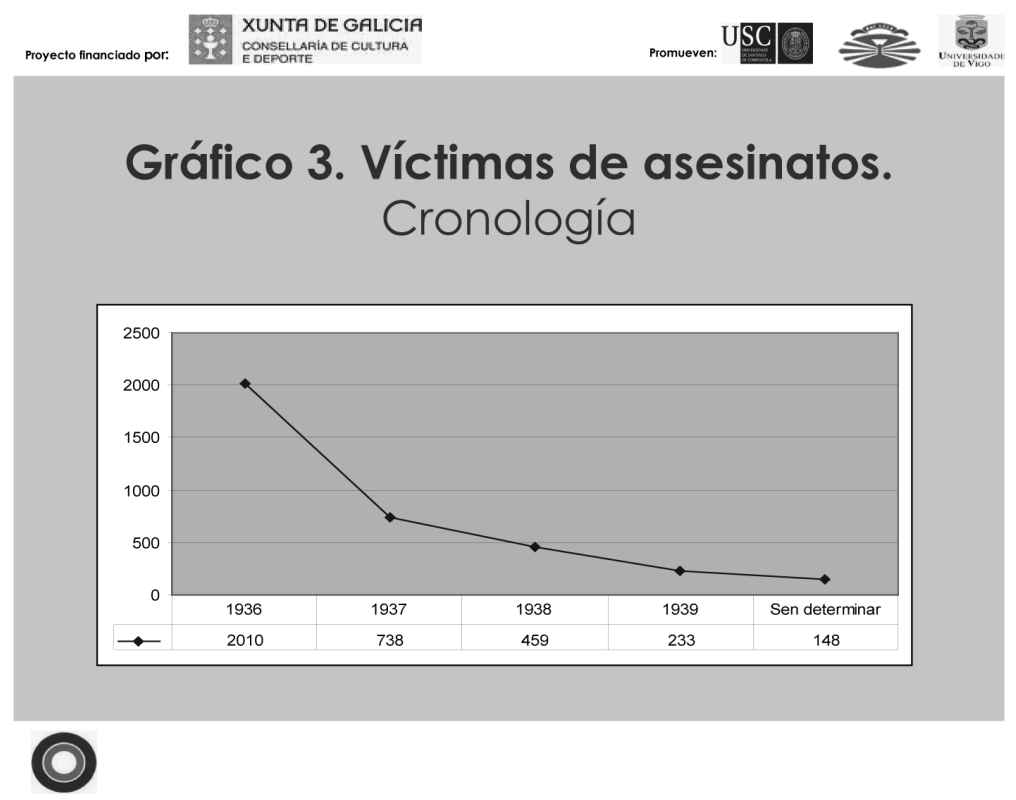

Fuente: Proyecto «Voces e Nomes»22.

Por último, la cronología de los asesinatos, y la concentración del 60\% de los mismos en los ocho primeros meses de guerra refuerza la idea de un terror paralizante destinado además a desalojar del poder por eliminación a todos los cuadros políticos y sociales relevantes de la República. A los que detentaban o representaban el poder del régimen que la sublevación militar quiere derrocar.

Resulta evidente que sobre los datos presentados puede y debe realizarse un análisis más demorado, destinado a arrojar más luz sobre el fenómeno represivo. En futuras publicaciones el proyecto ofrecerá una interpretación más exhaustiva y demorada de los mismos. También es necesario resaltar que se trata de una parte de los disponibles y que muchos pueden ser desagregados para facilitar su interpretación. No obstante, su relevancia y la fiabilidad de la información recopilada -incluso con las cautelas expresadas- me han inclinado a su publicación, en este caso en cuanto formaron parte de la presentación que hice en su día en el curso que da soporte a esta publicación ${ }^{23}$.

22. Idem gráfico 1 .

23. Por lo demás avances de los mismos fueron presentados ya en varias ocasiones y pueden consultarse en la página web del proyecto www.nomesevoces.com. 


\section{El trabajo en los registros civiles de defunciones. Apunte de una problemá- tica}

El trabajo de pesquisa desarrollado en los registros civiles de Galicia resultaba esencial para poder dilucidar el número aproximado de asesinados a causa de la represión extrajudicial acontecida en Galicia entre 1936 y 1939. La experiencia resultó en sí misma un interesante (y preocupante) termómetro para medir la temperatura del problema de acceso a las fuentes del período, así como de las sensibilidades sociales y de algunas instituciones del Estado respecto al trabajo de investigación de los historiadores sobre estas cuestiones.

En primer lugar, se realizaron las visitas a las principales ciudades de Galicia: A Coruña, Compostela, Ferrol, Lugo, Pontevedra, Vigo, Tui, Vilagarcía y Monforte de Lemos. Nos encontramos diversos problemas por la negativa de algunos jueces a facilitarnos el acceso a los libros de defunciones. Por este motivo, el Proyecto solicitó la intervención del Presidente en Funciones del Tribunal Superior de Xustiza de Galicia en abril de 2007 que facilitó que los registros de Pontevedra, Vigo y A Coruña fuesen abiertos a los investigadores.

La problemática que afectó a los trabajos con los registros civiles fue muy variada, dependiendo de si el registro en cuestión era el de la capital del partido judicial o el de un juzgado de paz. Los problemas comenzaron con Vigo y Pontevedra, donde los jueces responsables se negaron a facilitar los datos de los libros de defunciones alegando la no difusión de datos personales y A Coruña, donde el juez responsable aducía falta de espacio y de personal para poder atender a «peticiones masivas» como la que le estábamos realizando. La intervención del Presidente en Funciones del Tribunal Superior de Xustiza de Galicia, D. Antonio González Nieto, se concretó en una carta en que recomendaba a todos los responsables de los partidos judiciales de Galicia que se facilitase la visita de los investigadores atendiendo a la legislación vigente: respetar los horarios de cada registro y realizar la visita en el momento en que los funcionarios pudiesen atendernos con la menor alteración de su trabajo diario. Además desde el proyecto nos apoyamos en las resoluciones que confirmaban la posibilidad de que los historiadores accediesen a esta información: Resolución de la Dirección General de Registros de marzo de 2007, Resolución del B.O.E de agosto de 2007, así como la respuesta a la interpelación del grupo parlamentario del GV-PNV en el Congreso de los Diputados en septiembre de 2004.

Para acometer la tarea de vaciado de todos los registros civiles se planificaba una ruta de visita a los registros civiles, previamente se notificaba por teléfono o por carta a cada registro (según la opción que estimaban los propios funcionarios) y se procedía a su vaciado para los años 1936-1939. Aun así, persistieron los problemas: horarios increíbles (de mañana o tarde o en fines de semana); 
desconocimiento (activo o pasivo) -por parte, sobre todo, de los jueces de paz municipales- de la legislación que permitía el acceso a esta documentación; falta de personal, que obligaba a aplazar viajes por causa de enfermedad, vacaciones o cambio de trabajo de los responsables de cada archivo; el mal estado de conservación de la documentación o del edificio que la alberga; «desaparición» incluso del funcionario encargado de atender al público; o interrupciones al trabajo de los investigadores aduciendo la ley de protección de datos que acaparaba a los inscritos. Todas estas circunstancias fueron la causa de la dilación de esta fase del trabajo en más de un año. Especial mención merece el modo de comunicación con cada registro civil, siempre por correo postal; tan sólo en tres ayuntamientos (Cervo, Carballedo y O Saviñao) permitieron las consultas vía correo electrónico.

Finalmente, además de obtener los datos de la mayoría de los 315 ayuntamientos de Galicia, se logró la apertura de estos archivos a la investigación, venciendo -aparentemente de modo definitivo- las restricciones que habían afectado a numerosos investigadores hasta el momento ${ }^{24}$. Es necesario reseñar, sin embargo, que la destrucción física de algunos registros civiles de varios ayuntamientos de la provincia de Coruña obliga a recurrir como fuente alternativa a los registros parroquiales, para los que las diócesis correspondientes todavía no nos han dado autorización.

\section{Balance provisional}

Para su desarrollo, el proyecto ha requerido de una importante colaboración social, imprescindible para la realización de 450 entrevistas, hay que decir que, si bien la respuesta social es positiva, en el caso de las asociaciones dedicadas a la recuperación de la memoria de estos hechos la respuesta fue diversa, aunque a medida que el Proyecto avanza -y se va consolidando la confianza- se incrementa la participación en el mismo, tanto de asociaciones, recelosas en principio con el papel de la Universidad y la historia académica, como en el caso de los investigadores autodidactas.

Desde su puesta en marcha, el proyecto ha constituido un comité asesor, en el que ha sido invitado a participar un buen número de los investigadores de la represión y el franquismo en Galicia. También se ha establecido desde un

24. Para la realización del trabajo «Golpe de Estado y represión franquista en la provincia de Pontevedra» de Ángel Rodríguez Gallardo (Prada, Julio y Juana, Jesús de, Lo que han hecho en Galicia, Barcelona, Crítica, 2006, pp. 135-164), el juez de Pontevedra denegó formalmente el vaciado del registro de defunciones de la ciudad según resolución de mayo de 2005. 
principio un grupo de evaluación y control en el que participan Ángela Cenarro y Conxita Mir. Ambos mecanismos sirven al proyecto para presentar resultados parciales, discutirlos y definir nuevas vías de indagación o corregir las establecidas, formular nuevas preguntas y orientar los derroteros de las pesquisas del equipo.

El desarrollo del proyecto de investigación, la experiencia acumulada en su ejecución y el volumen, cualidad y novedad de los datos obtenidos ha permitido algunos interesantes resultados. Entre otros, dos libros de A. Míguez Macho, activo investigador del proyecto durante dos años, en los que, en línea con el auto del juez Garzón que define los asesinatos de la Guerra Civil como crímenes contra la humanidad, argumenta de una forma muy consistente la conceptualización de dichos crímenes como genocidio y no como represión, a la vez que cuestiona la reiteración del recurrente paradigma investigador utilizado en las últimas décadas para el estudio de la represión en España ${ }^{25}$. Otro investigador del proyecto, Andrés Domínguez Almansa, analiza las memorias de los supervivientes y de sus familias para definir nuevos mecanismos de tratamiento e interpretación de los relatos orales que dan soporte a las memorias sobre la represión $^{26}$. Éstos y otros trabajos son un ejemplo de la riqueza de la experiencia investigadora acumulada, así como de las posibilidades de interpretación que ofrecen los datos recopilados.

El reciente cambio de Gobierno en la Xunta de Galicia después de las elecciones de marzo de 2009 ha tenido como consecuencia la interrupción, en diciembre de este mismo año, del convenio que daba soporte al proyecto de investigación.

Anexo 1) Algunas acciones a tener en cuenta:

Septiembre de 2006 Congreso de los Diputados: Proyecto de ley «Por la que se reconocen y amplían derechos y se establecen medidas en favor de quienes padecieron persecución o violencia durante la Guerra Civil y la Dictadura».

25. Míguez Macho, Antonio, O que fixemos en Galicia. Ensaio sobre o concepto de práctica xenocida, Ourense, Difusor de Letras, Artes e Ideas, 2009, y Xenocidio e represión franquista en Galicia, Santiago, Edicións Lóstrego, 2009.

26. Domínguez Almansa, Andrés, «De los relatos del terror al protagonismo de la memoria. El golpe de Estado de 1936 y la larga sombra de la represión», Historia y Fuentes orales, 40 2008, pp. 37-74. 
Diciembre de 2006 el Parlamento Gallego aprueba una proposición no de ley para la «rehabilitación xurídica, persoal e moral de Alexandre Bóveda, e de todas as persoas asasinadas e represaliadas por defenderen a legalidade democrática, as aspiracións de autogoberno de Galicia e a xustiza social».

Solicita al Gobierno del Estado «as accións necesarias que permitan a anulación dos consellos de guerra a que foron sometidos». La moción fue aprobada con la abstención del PP y los votos a favor de BNG y PSdG-PSOE.

El 26 de marzo de 2008 el Parlamento de Galicia aprueba una iniciativa del BNG para eliminar la simbología franquista de los centros educativos. Votos a favor PSdG-PSOE y BNG, en contra los diputados del PP.

Anexo 2) Ficha de vaciado de fuente del proyecto para la construcción de la base de datos de Nombre de víctimas de la represión.

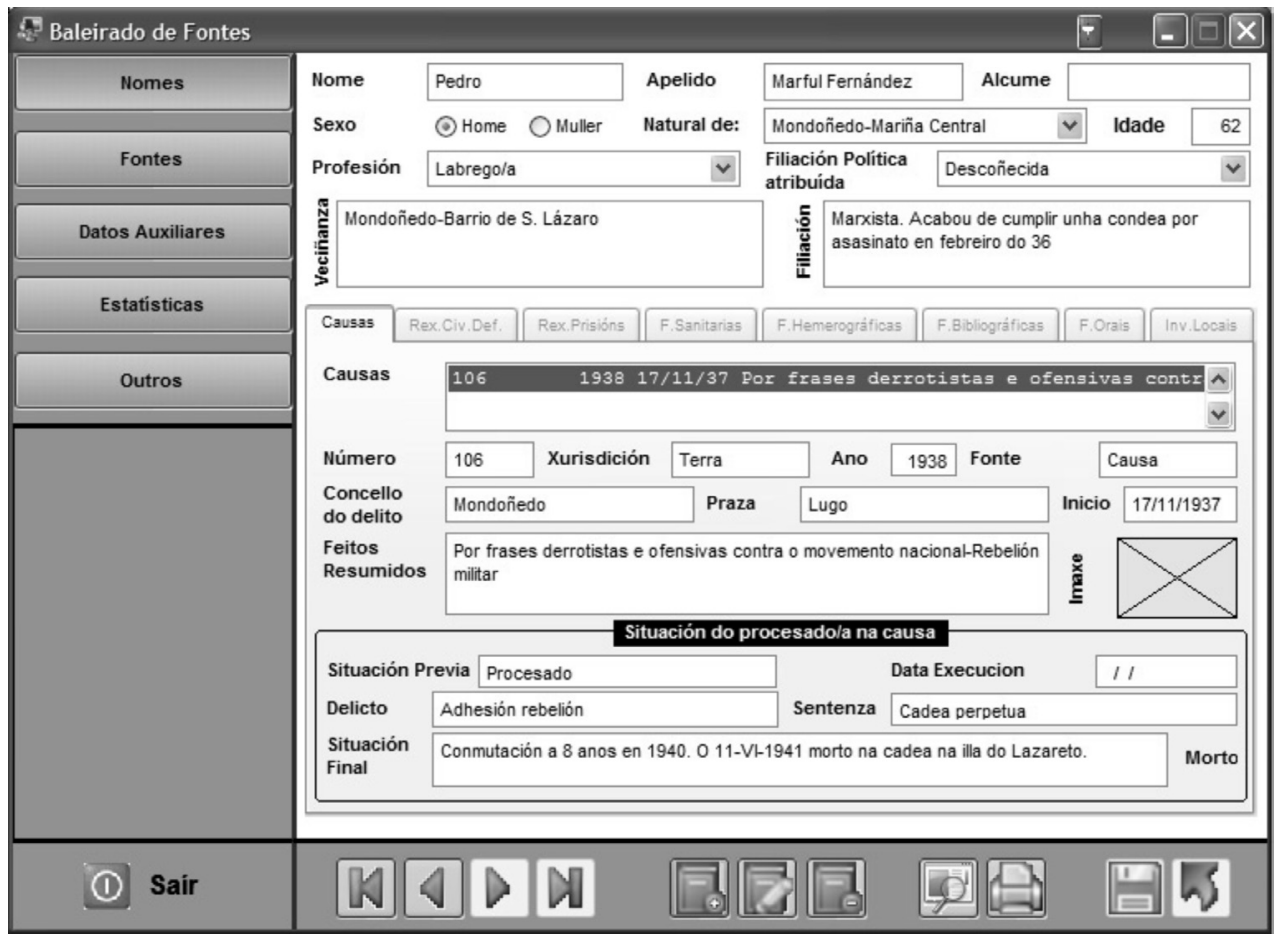

Pasado y Memoria. Revista de Historia Contemporánea, 8, 2009, pp. 131-157 